\title{
Negative school experiences of Late Millennial Korean medical students: a qualitative study using the critical incident technique
}

\author{
HyeRin Roh', So Jung Yune ${ }^{2}$, Kwi Hwa Park ${ }^{3}$, Geon Ho Lee ${ }^{4}$, Sung Soo Jung ${ }^{5,6}$ and Kyung Hee Chun ${ }^{7}$ \\ ${ }^{1}$ Department of Medical Education, Inje University College of Medicine, Busan, ${ }^{2}$ Department of Medical Education, \\ Pusan National University School of Medicine, Yangsan, ${ }^{3}$ Department of Medical Education, Gachon University \\ College of Medicine, Incheon, ${ }^{4}$ Department of Family Medicine, Catholic University of Daegu School of Medicine, \\ Daegu, Departments of ${ }^{5}$ Medical Education and ${ }^{6}$ Internal Medicine, Chungnam National University College of \\ Medicine, and ${ }^{7}$ Department of Medical Education, Konyang University College of Medicine, Daejeon, Korea
}

Purpose: Today's students have distinctive generational characteristics and increased psychopathology and generational tension. The authors investigated the negative experiences of Late Millennial students in medical school to draw implications for student support.

Methods: The authors explored medical students' negative experiences using the critical incident technique. The authors conducted semi-structured in-depth interviews with 13 medical students, between February and May 2016. The authors focused on occurrences that significantly influenced medical students' school lives negatively from the students' perspective. All interviews were recorded and transcribed. The authors classified incidents into frames of reference for the use of faculty development for student support. Results: The authors extracted 22 themes from a total 334 codes and classified them into eight subcategories. Finally, four categories emerged from frames of reference. Students manipulate relationships and colluding for better specialty choice. They experience uncontrolled rifts in interpersonal relationships between peers including lawsuits, sexual assaults, and social network service conflicts. Today's students feel resentment towards dependent hierarchical relationships with seniors. They struggle with gender discrimination but perpetuate outdated gender role toward the opposite gender.

Conclusion: Faculty members should understand today's students' level of career stress and desire for work life balance. They should motivate students' professional identity, promote assertiveness against unfair authorities, and focus on mental health, teamwork, and relationship building. All generations need to understand other generations and develop appropriate leadership and gender sensitivity.

Key Words: Characteristics, Conflicts, Stress, Medical education, Qualitative research

\section{Introduction}

Generational tension between faculty and students in medical education contexts has recently been frequently reported [1,2]. Faculty members report feeling perplexed and frustrated when faced with today's students' unexpected behaviors, feelings, and thoughts [2]. The literature describes generational conflicts over attitudes towards lectures, posting content on social network
Received: March 26, 2020 • Revised: May 10, 2020 • Accepted: June 18, 2020 Corresponding Author: So Jung Yune (https://orcid.org/0000-0002-2567-0444) Department of Medical Education, Pusan National University School of Medicine, 49 Busandaehak-ro, Mulgeum-eup, Yangsan 50612, Korea

Tel: +82.51.510.8025 Fax: +82.51.510.8125 email: cc139@pusan.ac.kr
Korean J Med Educ 2020 Sep; 32(3): 197-211.

https://doi.org/10.3946/kjme.2020.167

eISSN: 2005-7288

(C) The Korean Society of Medical Education. All rights reserved. This is an open-access article distributed under the terms of the Creative Commons Attribution Non-Commercial License (http:// creativecommons.org/licenses/by-nc/3.0/), which permits unrestricted non-commercial use, distribution, and reproduction in any medium, provided the original work is properly cited. 
services (SNS), and email communication etiquette [3-5]. Additionally, faculty have reported critical incidents related to student misconduct using digital technology and highly stressful situations that were beyond the professors' capacity to detect [2].

Millennials as being born beginning in 1981 and they are the children of the Baby Boomers and the younger siblings of the Generation Xers. Current students are from the Late Millennial generation, born from 1987 to 1995 [6]. They are also known of as 'Recessionist Millennials' because they were significantly influenced by the Great Recession [6,7].

Definite generational differences are increasingly reported in the literature $[1,8,9]$. Some researches shows that Late Millennials have distinct characteristics from Early Millennials although they share common Millennial characteristics [8-10]. Debevec et al. [6] report Late and Early Millennials both have similar attitudes toward confidence, team-play, and pursuing their dreams, but Late Millennials are less likely to value saving money, religion, and their virginity.

Studies have reported that younger generations are more 'miserable' than past generations, although they grew up in increasingly more child centered environments [8,11]. According to Twenge's birth cohort analysis, psychopathology significantly increases with each generation [12]. Furthermore, recent college records show that today's students seek assistance for mental health problems more frequently than past generations [13]. Recent medical students require more extensive supportive care [14]. These trends indicate an increased need for psychosocial support to ensure students' happiness in medical school.

A large number of Faculty are interested and passionate about student education in medical school, but there are difficulties caused by the lack of understanding that comes from generational gap. They may unintentionally overlook students' difficulties because of the generational gap. Eliminating the 'blind spots' of today's faculty members may help them support students to better adjust to medical school. Most studies focus on student characteristics based on quantitative surveys or literature reviews [15]. There is a lack of research presenting in-depth accounts of the experiences encountered by Late Millennial medical students (especially negative experiences) in medical school. Therefore, this study aims to focus the generation gap and perception differences between faculty members and the late millennium students. Understanding what Millennial students have experienced will help faculty members overcome gaps between generations. One of the qualitative research methods dealing with the subject's experiences is the critical incident technique (CIT).

Critical incidents may clearly reveal hidden episodes and vividly explain the difficulties faced by today's students. Understanding negative incidents may be effective to detect and help prevent the problems faced by today's students. Therefore, this study investigates negative revelatory experiences of today's medical students using a CIT. The aim of the study is to broadly overview negative critical incidents to discover new and emerging issues where today's medical students need support. The results of this study can help faculty in medical schools understand Late Millennial students, and provide basic data to prepare support strategies to help students better adapt to school. The research question is "which negative critical incidents have occurred to Late Millennial students in Korean medical school?"

\section{Methods}

\section{Study design}

We selected the CIT to explore negative events 
experienced by medical students in depth. The CIT is a qualitative research method which is useful for gathering in-depth and rich details of significant factual episodes, particularly in lesser known topics, from the perspectives of the participants $[16,17]$. In this study, we determined critical incidents as negative occurrences in medical school that significantly influenced students' lives from the student's perspective. The general faculties were, for the most part, unable to recognize the incidents' significance or notice it happening. We focused on representative incidents experienced by Late Millennial students and excluded positive issues such as extracurricular activities. Additionally, we excluded negative issues which were covered in the literature, including high expectations toward scores, desire for work life balance, usage patterns of information technology (IT), complaints about the physical environment, academic stress, limited relationships within medical society, negative experiences with patients, and financial issues. We chose individual interviews rather than focus groups to allow participants to easily disclose their experiences without fear that others may hear their stories and to allow researchers to explore stories in greater depth. Rather than ranking common incidents quantitatively, we qualitatively classified the full spectrum of critical incidents.

\section{Researchers}

We belong to Generation X, born from 1966 to 1976. Three majored in medicine and three majored in education. Four are women. We have significant experience providing student support and mentoring. K.H.C. is a CIT expert. We have several years' experience performing qualitative research. We chose H.R. (medical doctor) and S.J.Y. (education $\mathrm{PhD}$ ), who are experienced interviewers in curriculum evaluation, admission selection, and qualitative research, to conduct the interviews.

\section{Participants}

Participants in the study are the Korean medical school students. The students have experienced high competitive educational environment since middle school in Korea. Most Korean medical schools have norm-referenced evaluation and a "drop out" system. The curriculum generally consists of 2 years of classroom education and 2 years of clinical clerkship in a hospital. Students are required to take a Korean Medical Licensing Examination to practice as a doctor in Korea.

Table 1. Demographics of Interviewees

\begin{tabular}{clclcc}
\hline Students & Gender & Age (yr) & \multicolumn{1}{c}{ Location } & Marriage & Grade \\
\hline 1 & Male & 25 & Busan & Single & 3rd \\
2 & Female & 28 & Gyeongsang-do & Single & 4th \\
3 & Female & 25 & Chungcheong-do & Single & 3rd \\
4 & Female & 23 & Jeolla-do & Single & 3rd \\
5 & Male & 23 & Jeolla-do & Single & 3rd \\
6 & Female & 24 & Seoul & Single & 3 rd \\
7 & Female & 24 & Seoul & Single & 4 th \\
8 & Male & 26 & Seoul & Single & 3 rd \\
9 & Male & 23 & Seoul & Single & 2nd \\
10 & Male & 26 & Seoul & Single & 2 nd \\
11 & Male & 28 & Seoul & Single & 2 nd \\
12 & Female & 26 & Seoul & Single & 2nd \\
13 & Female & 26 & Seoul & Single & 4th \\
\hline
\end{tabular}

All of study participants are Late Millennials as graduated students. Fourth year is final year. 
We recruited interviewees via the Korean Medical Student Association and the Student Councils of each of Korea's 41 medical schools. We asked the participating student association and councils to announce study recruitment to currently enrolled medical students born between 1987 and 1995. We selected a range of potential volunteers according to demographic distribution in order to maximize representation from within the Late Millennial generation. Finally, we selected participants so that bias would not appear due to the imbalance in gender, grade, and regional distribution. Then, we emailed selected volunteers to provide detailed information about the research and ask further questions about their demographics. Finally, 13 students participated in this study (Table 1).

\section{Materials and analysis}

We developed the frame of the semi-structured interview question with reference to the CIT interview technique over several meetings with researchers [18]. We conducted a preliminary interview two students. We revised questions using feedback of the interviewees. We classified the questions into a framework with academic and non-academic issues (Table 2). We conducted interviews between February and May 2016. We met each volunteer at a location and time selected by them. To preserve confidentiality and anonymity, we only liaised with the participants. Before starting the interview, we again explained the research and interview process in detail and obtained participants' written informed consent. Interviews were recorded with the

\begin{tabular}{ll}
\hline Table 2. Framework of Interview with Interview Questions \\
\hline Main question & Could you tell me the most significant negative experiences in medical school? \\
Sub questions & 1. What was the context in which the incident occurred? \\
& 2. How did you feel when you encountered it? \\
& 3. What did you think about it? \\
& 4. What did you do in that situation? \\
& 5. What were the consequences of your actions? \\
& Academic experiences \\
& During lectures and self-directed learning \\
& Small group activities \\
& During exam \\
& Learning ethics, cheating \\
& Students evaluation of faculty's instruction and others \\
& Non-academic experiences \\
& Relationship with classmates \\
& Relationship with senior or junior students \\
& Relationship with faculty \\
& Relationship with family \\
& Romantic relationship \\
& Internet, SNS, or games \\
& Sexual or physical violence \\
Career choice & Volunteer activities and others \\
& Competence to develop more \\
& Need for support from school and faculty \\
\hline
\end{tabular}

SNS: Social network service. 


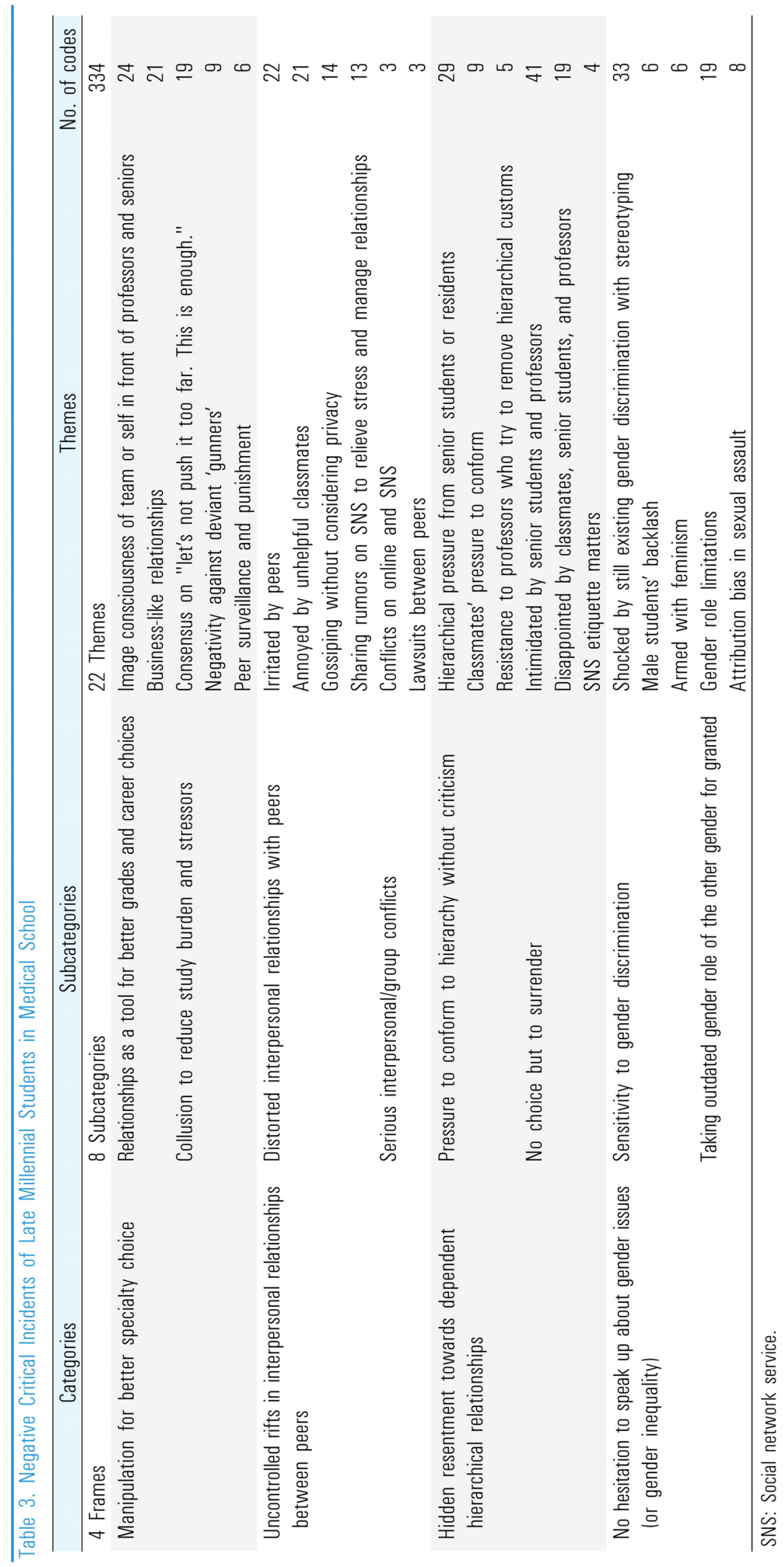


participants' consent. We interviewed each volunteer until no new negative incidents emerged. The duration of each interview was around 1-2 hours. All recorded interviews were transcribed verbatim. H.R., S.J.Y., and K.H.C. independently read all transcripts, labelled codes, clustered and categorized themes, and linked the themes to representative interview quotes. H.R., S.J.Y., and K.H.C. also cross checked and discussed the codes, themes, and quotes of preliminary results. Then, G.H.L., K.H.P., and J.J.S. reviewed the preliminary results. All researchers reviewed, modified, and discussed the results until a consensus was reached. During results analysis, we discussed characteristics of Generation $\mathrm{X}$ to reduce our prejudice.

\section{Credibility/trustworthiness checks}

We checked the results' credibility and trustworthiness according to the recommendations of Butterfield et al. $[18,19]$. Interviewees cross-checked the provisional report including critical incidents and quotes. One critical incident was removed, and one was revised based on feedback from the interviewees. Both were related to online experiences. In order to check trustworthiness, we sent the revised results to three external independent judges and two external experts. The external judges are from the Early Millennial generation. They are an Australian medical communication specialist, a professional translator, and a surgeon. External experts are faculty from the Baby Boomers generation with significant medical education experience.

\section{Ethical approval}

The research was ethically approved by the Pusan National University Institutional Review Board (PNU IRB/2016_20_HR).

\section{Results}

We categorized incidents into four frames of reference from the perspective of faculty development for the provision of student support (Table 3, Appendix 1). We extracted 464 codes then excluded 130 codes which were not related to our research questions. Finally, we identified 22 themes from the remaining 334 codes, and classified them in to eight subcategories.

\section{Manipulation for better specialty choice}

In this category, we extracted two subcategories with five themes from a total of 79 codes (Table 3). Subcategory themes were "relationships as a tool for better grades and career choices" $(\mathrm{n}=45)$ and "collusion to reduce study burden and stressors" ( $n=34)$. Students' main motivation to get good grades was to facilitate better specialty choices. Students believed good relationships provided the foundation for achieving good grades. They also believed good scores could enable them to attain the specialty that they wanted. Despite this, students did not want to study to the extent that previous generations typically studied to achieve good grades. Students secretly used (and in some cases misused) IT for school work.

Students were very conscious of their own image and/or that of their team $(n=24)$. They wished to impress their seniors, residents, and professors because they believed their future career depended on those people. Students needed to get along with other people in medical school and entered into relationships with their peers based on whether they considered the acquaintance to be advantageous to their grades or future. Although students wanted to establish deeper connections with people, their relationships remained superficial $(n=21)$. 
They tend to be really polite to the professors they know $\cdots$ because they are the ones who always affect our lives. (S5)

There's a tendency to try to change everything to make it work for themselves. (S1)

Clubs are not for your interests or hobbies. They're about making the right connections. (S12)

It's like we're just connected by work. I can't talk to my peers about the things that bother me the most. The most nerve-wracking and hardest thing is grades, but I can't really talk about that with my peer group $\cdots$ Peers are both the easiest and hardest thing. (S6)

Students colluded with each other to create and maintain secret rules of their own in order to reduce their academic burden $(n=19)$. They presented negativity and sometimes hostility towards overly competitive or rule deviant peers $(n=9)$. Students reacted very sensitively to rule-violation or cheating behaviors and monitored classmates for them. When students discovered rule breakers, they punished them publicly $(n=6)$.

Everyone in my grade is like, "let's not push it too far. This is enough." (S3)

There's this girl in our class who's a gunner who always wins first place. She's got a bad image. (S7)

We're pretty sensitive to cheating. We recently decided to give a punishment to a [cheating] student ourselves.

\section{Uncontrolled rifts in interpersonal relation- ships between peers}

In this category, we extracted two subcategories with six themes from a total of 76 codes (Table 3). Subcategory themes were "distorted interpersonal $\mathrm{re}^{-}$ lationships with peers" $(\mathrm{n}=70)$ and "serious interpersonal/ group conflicts" $(\mathrm{n}=6)$. Students experienced severe interpersonal conflicts between their peers in medical school.

Students confessed that they became easily irritated by their peers during the exam period $(n=22)$. They reported that they frequently experienced their own or their peers' mental health problems such as paraphilia, posttraumatic stress disorder, anxiety, paranoid behaviors, schizophrenia, depression, or suicidal tendencies. They wanted to be cared for but expressed difficulty caring for others $(n=21)$.

The more tests we take, the more irritated we become.$\cdot$ we have more fights towards the end of semester $\cdots$ At the end of the semester, we're irritated by pretty much anything and anyone around us. (S1)

It's like everyone is a patient. We all need psychotherapy. (S12)

At first, we help someone with a good intention, but it's not easy if it [dependent behavior] continues. (S11)

Students gossiped about others' affairs to relieve interpersonal stress $(n=14)$. They shared the private affairs of others in person and via SNS ( $n=13)$. Students considered SNS and games as social tools and denied they were addicted to them. However, they said a few students were addicted to SNS or games.

There're are no secrets $\cdots$ one minute one or two people figure something out, the next everyone knows $\cdots$ (S11) In group chats $\cdots$ we talk about everything. Like incidents and accidents $\cdots$ gossip. (S6)

I am a little hooked on SNS sites $\cdots$ but when I look at my peers $\cdots$ I don't think they have an addiction $\cdots$ maybe that's because they're busy studying $\cdots$ or they can't possibly spend much time [on SNS]. (S8) 
Students witnessed hatred among their peers. They sometimes experienced online bullying or violence $(n=3)$. They had heard about lawsuits between peers $(n=3)$.

Things start small but then develop into big arguments. Then, they barely speak to each other $\cdots$ once the rift gets deep, these people just continue to be divided. (S10) Usually SNS sites are the cause of incidents. When normal communication gets blocked, serious problems pop out in strange directions, like SNS. (S1)

There was a lawsuit among us. (S9)

\section{Hidden resentment towards dependent hierarchical relationships}

We extracted two subcategories with six themes from a total 107 codes in this category (Table 3). The subcategory themes were "pressure to conform to hierarchy without criticism" ( $\mathrm{n}=43)$ and "no choice but to surrender" ( $n=64)$. Senior students and residents were the main source of hierarchical pressure. Students felt shocked at first but easily surrendered to the pressure. Students described their experiences of a hierarchical orientation for freshmen and many other mandatory situations enforced by senior students $(n=29)$. Although students complained that senior students pressured freshmen or junior students, they continued the tradition without criticism when they became senior students themselves. They felt uncomfortable when they saw junior students who were not respectful. Classmates persuaded them not to speak up and instead follow irrational authoritative customs $(n=9)$. Some students voluntarily over-observed these customs although they were not mandated. They resisted some professors' attempts to remove hierarchical customs ( $\mathrm{n}=5)$.

Fourth year seniors call freshmen and sophomores to come out and force them to drink. (S6)

The male students, used to strongly complain about having to drink like $\mathrm{h}^{* * 1}$ with seniors $\cdots$ now that they are seniors themselves, they force their juniors to drink. (S7)

I think junior students should be little politer $\cdots$ (S5)

One classmate told me that I shouldn't talk to the seniors like that and I should just humor them. (S2)

Our class representative made a student code. He thought things should be done better and no one should make mistakes. He took things seriously and made a notice $\cdots$ and passed it out to peer female students $\cdots$ you know something like wearing no makeup, tying hair up, and wearing shoes with less than 3-cm heels. (S4) Professors think this is a very dangerous culture. As a student representative, I don't want them [the professors] to take it too seriously. (S3)

Students said they felt intimidated to see professors, residents, and senior students because they feared being scolded $(n=41)$. They had been stifled by classmates who persuaded them to give up resisting and instead obey customs ( $n=19)$. Students also felt disappointed in senior students and professors who emphasized hierarchy but did not show professional behavior including appropriate SNS etiquette, respect for people, sexual ethics, and consideration for diversity. They were confused by professors' emphasis on respectful attitudes and horizontal relationships. Some students experienced frustration with professors' texting etiquette $(n=4)$.

Mostly I'm a bit scared $\cdots$ I don't see that the professors take care of me. I have to serve them. (S4)

The residents are really hard on us. I mean, some of them are nice but overall, they've got a vibe that makes it hard to reach them. (S6)

Freshmen are a bit scared of seniors. (S5) 
As I moved up to the next grade, I just gave up and decided to keep up with things. Even if I said something, nothing would change. (S2)

Some professors treat everyone badly, depending on how they feel. (S8)

Professors said we can ask them about anything. So, we actually asked random questions and we got scolded. (S13) I once sent a message to this professor at 9:30 PM $\cdots$ he scolded me a lot. (S9)

\section{No hesitation to speak up about gender issues (or gender inequality)}

We extracted two subcategories with five themes from total 72 codes in this category (Table 3). Subcategory themes were "sensitivity about gender discrimination" $(n=45)$ and "taking outdated gender roles of the other gender for granted" $(n=27)$. Students strongly felt that gender discrimination was a problem and did not hesitate to speak up if they felt they were discriminated against. Female students had never actually faced discrimination or felt the need to advocate for their rights before entering medical school, but in the medical field they experienced gender discrimination with stereotyping $(n=33)$. Furthermore, female students were verbally attacked in public by male students who felt their own place was threatened by female students $(n=6)$. Female students felt deeply disgusted by gender stereotyping and stigmatization with vicious rumors about females and so they armed themselves with feminism $(\mathrm{n}=6)$.

When I started first year in medical school, I thought, why do we need a female student council? Are women weak? (S3)

Guys seem to have a 'little victim' mentality towards girls. (S6)

The issue on my mind most these days is gender discrimination $\cdots$ I don't think I can find sexual discrimination in medical school or the curriculum ... but in actual hospitals. (S7)

There are times when I hear some men saying, "no matter how hard women study, some departments still won't hire them." (S7)

I think especially female students are talked about behind their backs, when we're drinking and gossiping. (S7) I attended classes on gender issues $\cdots$ I also learned a lot about gender stereotyping on TV $\cdots$ I realized that I lock myself a lot in the gender bias. (S6)

Students took outdated gender roles of their peers of the other gender for granted although they could not stand gender discrimination. They valued femininity in female students and limited female roles to supporters, mothers, or sexual objects. At the same time, they valued masculinity in male students and expanded male roles of strength, courage and the ability to protect "weak" females $(n=19)$. They experienced sexual assault between classmates and heard that women should "watch their behavior" ( $\mathrm{n}=8)$.

When I look at girls who guys think have good images, they are really quiet and submissive, don't have any opinions, and always smile. (S7)

Much of the work requires physical strength, so guys end up working more. (S6)

When a female doctor becomes pregnant, it's the end of her career. So, I think I should really be careful. Because of the oppression and fear, I can't really enjoy sex. (S7) I think there're some sexual issues. There are stories and there are some things I've actually seen. Usually when drinking too much, some guys don't know where to put their hands. (S1)

When this girl is really drunk, she is really $\cdots$ actually $\cdots$ what I can say $\cdots$ easy? (S8) 


\section{Discussion}

This study aimed to recognize a broad spectrum of students' negative experiences through in-depth interviews in order to uncover areas of need which may be supported by faculty. Students' pursuit of both good career choice and quality of life resulted in various negative incidents. The findings of this study may help remove faculty members' prejudices towards Late Millennial students and recognize emerging issues faced by today's students. However, there was a limit to dealing with all of generational differences in depth. Therefore this study focuses to discuss the negative and critical experiences of Late Millennial students in the medical school.

This study revealed that students manipulate their relationships and responsibilities to improve their grades and career prospects. Their desire was not to pursue excellence, but to avoid delivering a worse performance than their peers [20]. Today's students prefer a noncompetitive environment. Late Millennials are less likely to consider work as their identity than Early Millennials and are known for their 'YOLO' (you only live once) attitude [7]. Our results show that motivating students to study by exam scores alone may no longer be effective and may do more harm than good. How students function in an educational program is inextricably linked to how they are evaluated. The results suggest that norm-referenced evaluation system should be modified to encourage not competition but learning itself [21]. Additionally, educators are called to reform medical education to support professional identity formation while acknowledging the students' values and motivations including quality of life [22].

The second major category was "uncontrolled rifts in interpersonal relationships between peers." It consisted of "distorted interpersonal relationships with peers" and "serious interpersonal/group conflicts." These results indicate that team collaboration between peers at the medical school is taking place in a superficial state. Late Millennials favor team collaboration less than Early Millennials [7]. However, learning in today's educational environment is based on team activities. This requires students to manage the achievements and contributions of their team members because it affects their team scores and ultimately individual grades. However, team members can be unmotivated, mentally ill, dependent, or uncooperative. As a result, individualistic desires and peer dependence may cause severe conflicts within teams. We think small group work and group activities may not spontaneously develop positive teamwork skills. The results of this study strongly imply the necessity of further educating students about specific teamwork skills. However, since we did not directly ask how students think about team work, it is necessary to further study the concept of team work that students think.

There can be serious hierarchical conflicts between Early and Late Millennials or among Late Millennials. The results of this study indicate that today's students feel perplexed and frustrated when dealing with their seniors. Senior students and residents may also feel frustrated when they deal with the younger generation. Both inter- and intra-generational differences in expectations about favorable leadership styles, work ethics, and professional behaviors can cause conflict [7,8]. This study implies that faculty, students, and residents should all learn how to interact effectively with each other. Additionally, all generations should learn current professional behavior expectations [23].

Students considered feigned obedience as a good strategy for impressing professors, residents, and senior students. Previous generation favor respectful attitude [24]. Thus, students may feel obedience as a practical 
strategy because it is a manifestation of respectful attitude. However, respect is not the same as obedience, and blind or feigned obedience without critical thinking can infuriate professors and residents because it is risky for patient safety in clinical situation [25]. Physicians should be able to communicate effectively with anyone involved in the patient's treatment and be assertive for patient safety even in hierarchical culture. Today's students should understand the harmful potential of feigned obedience to patient safety. The results imply that more emphasis on the importance of assertiveness for patient safety is needed by today's students.

Students in this study experienced discrimination and sexual assault by peers as well as seniors during medical school. These results are consistent with recent reports in medical schools and clinical fields [26,27]. Career choice is critical to Late Millennial students, and both male and female students seem to feel their career threatened by the other gender. This study indicates that past diversity strategies targeting barriers to entry, mentoring minorities, and education to prevent sexual assault may not be sufficient. This study suggests that we should provide anti-discrimination and sexual ethics education for the benefit of all students, rather than focusing on the protection of minorities alone. Additionally, we should promote respect for diversity, gender equality, and sexual ethics to change cultures and systems and remove institutionalized prejudices.

This study shows that today's generation of students have divisive issues of conflicts. They want job stability but are unwilling to sacrifice quality of private life. They are individualistic, but team dependent. They are vulnerable to hardships such as academic burden, but do not know how to work through their problems. They want to be cared for but have to care for peers. They are dependent on authority but lack the social skills to deal with seniors [7]. They wish to perpetuate customs, but they need to change customs because of their diversity. We think these contradictory factors may negatively influence students' mental health and relationships. In the past, educators focused on counseling to prevent academic failure and suicide of a few troubled students. However, the results strongly suggest that developmental support focusing on mental health and relationships should be provided to all students [28,29].

The study has several limitations. First, interviews were conducted and analyzed in Korean and translated into English for publication. Translation was conducted by an experienced medical translator, however, due to differences in language structure and culture, there is a possibility that some meaning, or tone was altered. Second, the study participants are all Korean in Korean contexts. Therefore, specific cultural contexts, such drinking parties (which have different social connotations in western countries and Korea) are interpreted from the Korean cultural viewpoint. Third, there were 13 research participants in this study, and there were not enough to deal with the topics in depth. In particular, in order to draw meaningful conclusions about students' motivations and teamwork skills, in-depth studies involving a larger number of research subjects will have to be conducted.

The study showed the necessity of further research about generations. First, we should explore the four identified categories of Late Millennial students' characteristics in more depth. Second, we should study how to effectively interact with Late Millennials doctors in the hospital context because they now enter the workforce as residents and medical faculty. Third, we should examine Generation $\mathrm{Z}$ who are entering medical school now to identify their different characteristics [30]. Fourth, we should investigate the reasons why today's students are so different and less happy than previous generations in order to establish programs which meet their needs. Finally, we 
should investigate the experiences of Baby Boomers and Generation $\mathrm{X}$ faculty members to identify areas of frustration in order to better provide psychosocial support and faculty development.

In conclusion, current students pursued both good career choice and quality of life which led to diverse experiences of negative incidents. The results of this study strongly imply that an overhaul of the medical education system is needed. Areas that need to be addressed include (1) student motivation to inspire professional identity and patient centered assertiveness, (2) development of teamwork skills focused on mental health and relationship building, and (3) intra- and intergenerational training focusing on appropriate leadership and gender sensitivity.

\section{ORCID:}

HyeRin Roh: https://orcid.org/0000-0002-3879-709X;

So Jung Yune: https://orcid.org/0000-0002-2567-0444;

Kwi Hwa Park: https://orcid.org/0000-0002-0008-2400;

Geon Ho Lee: https://orcid.org/0000-0003-0696-3804;

Sung Soo Jung: https://orcid.org/0000-0001-7990-3066;

Kyung Hee Chun: https://orcid.org/0000-0002-5351-0376

Acknowledgements: The authors also wish to thank all interviewees for their participation in this study. The authors also wish to thank Lauren Nirta, Ju Hee Kim, Jiyoung Yun, Byoung Doo Rhee, and Young Hwan Lee for reviewing the results as external judges and experts.

Funding: No funding was obtained for this study.

Conflicts of interest: No potential conflict of interest relevant to this article was reported.

Author contributions: All authors are qualified for authorship. All authors participated in the initial study design and conceptualization. SJY recruited interviewees. HR and SJY conducted the interview. HR, SJY, and KHC independently coded the scripts and all authors were involved in data analysis and interpretation. SJY and HR drafted the initial article. All authors were involved in critically revising the initial drafts for important intellectual content and approved the final manuscript for submission. The authors agreed to be accountable for all aspects of the study in ensuring that questions related to the accuracy or integrity of any part of the work were appropriately investigated and resolved.

\section{References}

1. Twenge JM. Generational changes and their impact in the classroom: teaching Generation Me. Med Educ. 2009;43(5):398-405.

2. Lee GH, Chun KH, Yune SJ, Park KH, Jung SS, Roh H. Preliminary report: asking faculties about today's students. Paper presented at: symposium 1 of the 32nd Korean Medical Education Conference; May 26, 2016; Seoul, Korea.

3. Brisson GE, Fisher MJ, LaBelle MW, Kozmic SE. Defining a mismatch: differences in usage of social networking sites between medical students and the faculty who teach them. Teach Learn Med. 2015;27(2):208-214.

4. Kitsis EA, Milan FB, Cohen HW, et al. Who's misbehaving?: perceptions of unprofessional social media use by medical students and faculty. BMC Med Educ. 2016;16:67.

5. Kim DH, Yoon HB, Yoo DM, et al. Etiquette for medical students' email communication with faculty members: a single-institution study. BMC Med Educ. 2016;16:129.

6. Debevec K, Schewe CD, Madden TJ, Diamond WD. Are today's Millennials splintering into a new generational cohort? Maybe! J Consum Behav. 2013;12(1):20-31.

7. Bridgeworks. Connecting with three generational segments in the workforce: a survey comparing Early Millennials, Late Millennials \& Generation Z. http://www.generations. com/wp-content/uploads/2017/01/2017-BridgeWorks-3G 
-Report.pdf. Published 2017. Accessed March 10, 2020.

8. Sandeen C. Boomers, Xers, and Millennials: who are they and what do they really want from continuing higher education? Contin High Educ Rev. 2008;72:11-31.

9. Borges NJ, Manuel RS, Elam CL, Jones BJ. Differences in motives between Millennial and Generation X medical students. Med Educ. 2010;44(6):570-576.

10. Enright J. Millennial 411: how Millennial habits differ by age. https://civicscience.com/2017-report-millennials-habits/. Published December 2017. Accessed July 20, 2018.

11. Twenge JM. Generation Me: why today's young Americans are more confident, assertive, entitled and more miserable than ever before. New York, USA: Free Press; 2006.

12. Twenge JM, Gentile B, DeWall CN, Ma D, Lacefield K, Schurtz DR. Birth cohort increases in psychopathology among young Americans, 1938-2007: a cross-temporal meta-analysis of the MMPI. Clin Psychol Rev. 2010; 30(2): 145-154.

13. Beiter R, Nash R, McCrady M, et al. The prevalence and correlates of depression, anxiety, and stress in a sample of college students. J Affect Disord. 2015;173:90-96.

14. Elam CL, Borges NJ, Manuel RS. Millennial students' perspectives on the medical school learning environment: a pilot study from two institutions. Med Sci Educ. 2011; 21(2):151-157.

15. Jung SS, Park KH, Roh H, Yune SJ, Lee GH, Chun K. Research trends in studies of medical students' characteristics: a scoping review. Korean J Med Educ. 2017;29(3):137-152.

16. Flanagan JC. The critical incident technique. Psychol Bull. 1954;51(4):327-358.

17. Gremler DD. The critical incident technique in service research. J Serv Res. 2004;7(1):65-89.

18. Butterfield LD, Maglio AT, Borgen WA, Amundson NE. Using the enhanced critical incident technique in counselling psychology research. Can J Couns Psychother. 2009;43(4):265-282.
19. Butterfield LD, Borgen WA, Amundson NE, Maglio AS. Fifty years of the critical incident technique: 1954-2004 and beyond. Qual Res. 2005;5(4):475-497.

20. Linnenbrink-Garcia L, Middleton MJ, Ciani KD, Easter MA, O'Keefe PA, Zusho A. The strength of the relation between performance-approach and performance-avoidance goal orientations: theoretical, methodological, and instructional implications. Educ Psychol. 2012;47(4): 281-301.

21. Buja LM. Medical education today: all that glitters is not gold. BMC Med Educ. 2019;19(1):110.

22. Cruess RL, Cruess SR, Boudreau JD, Snell L, Steinert Y. Reframing medical education to support professional identity formation. Acad Med. 2014;89(11):1446-1451.

23. Roberts DH, Newman LR, Schwartzstein RM. Twelve tips for facilitating Millennials' learning. Med Teach. 2012;34(4):274-278

24. Taylor P, Keeter S. Millennials: confident. Connected. Open to change. Washington DC, USA: Pew Research Center; 2010 .

25. Walton MM. Hierarchies: the Berlin Wall of patient safety. Qual Saf Health Care. 2006;15(4):229-230.

26. Broad J, Matheson M, Verrall F, et al. Discrimination, harassment and non-reporting in UK medical education. Med Educ. 2018;52(4):414-426.

27. Jena AB, Khullar D, Ho O, Olenski AR, Blumenthal DM. Sex differences in academic rank in US medical schools in 2014. JAMA. 2015;314(11):1149-1158.

28. Sandars J, Patel R, Steele H, McAreavey M; Association for Medical Education Europe. Developmental student support in undergraduate medical education: AMEE guide no. 92. Med Teach. 2014;36(12):1015-1026.

29. Howe A, Smajdor A, Stöckl A. Towards an understanding of resilience and its relevance to medical training. Med Educ. 2012;46(4):349-356.

30. Seemiller C, Grace M. Generation Z goes to college. San Francisco, USA: Jossey-Bass; 2016. 


\section{Appendix 1. Example Incidents}

Theme 1. Manipulation for better specialty choice and work life balance

Their attitudes are totally different depending on if it's a professor or a teaching assistant. (S12)

There's no one I can open my heart and talk about anything with. Soulmates don't exist and there's no companionship. I've never even seen bullying or actual fights. Ever. (S9)

PBL? I try my best not to look stupid $\cdots$ actually, there's a computer in the PBL room and I can find the file before PBL starts. We check it out in advance. To see what's in there. It's really frustrating and hard when professors keep nitpicking us and we think 'Gosh, what am I doing here?' ... so, everyone has a goal to find the answers in advance and give them just right to suit the professors' tastes just like a fixed scenario and just get things over and done with as fast as possible. (S6)

If a certain professor likes questions, we take turns to ask questions, no matter what ... When we feel like our images are about to get damaged, we're all like "let's suck it up and ask questions" ... LOL like … other than that, we say, "let's try to not ask questions". (S12)

There's this guy in our class who is really irresponsible $\cdots$ never follows certain rules, if he doesn't like something, he says so, breaks our rules, does whatever he wants $\cdots$ contacts professors directly. (S6)

Someone went online during a test and checked out something. After all, at that time, the person who we thought was cheating came out in person and apologized publicly. But similar things happened again $\cdots$ so our classmates fought with each other about that and had an argument ... We recently decided to give a punishment to a [cheating] student ourselves. The penalty is not being able to take an exam in one subject so that their grades will come out low $\cdots$ that students won't [be able to] study at all before the test. (S8)

Theme 2. Uncontrolled rifts in interpersonal relationships between peers

He hysterically stormed out of the classroom $\cdots$ Suddenly he went to his roommate and kneeled in front of him begging him not to hit him or hurt him. It all happened in the corridor. His roommate wasn't a bad guy. He was just a little tough $\cdots$ There's a professor who pushed hard during PBL. The guy [who was yelling] had hard time too. So he recently had another attack. (S11)
One guy in my peer group has schizophrenia. He got really mad and he put it all on a girl, and backed her up against a wall. She was really hurt $\cdots$ We were told to take care of this guy during the clerkship round. We heard it continuously from every department we visited. It was kind of hard because it's hectic during clerkship. Everything's new and it's almost impossible to take care of ourselves. (S9)

This is the way we relieve academic stress here. Once somebody does something wrong, people make rumors and attack them. And then it moves to the next person $\cdots$ I see it as people always gossip about somebody doing something. When something happens, everyone knows about it the next day. But sometimes, the rumors get exaggerated $\cdots$ (S2)

Now it's not playing pool or cards but playing [online] games. Games are advantageous, especially to guys ... Juniors can interact with scary seniors through games ... Some people become close and interact with each other simply because of these games. I don't think we can just consider games as addictive and dangerous. (S9)

I've heard that every school has SNS groups, and they divide and fight with each other $\cdots$ SNS is built on anonymity ... So you can slander other people by mimicking them $\cdots$ they make incredibly surprising plans [to slander other people.]'. (S1)

They fought during clinical rotations $\cdots$ and $\cdots$ pushed each other. But that $\cdots$ one of the seniors in the fight's husband was a lawyer. So $\cdots$ she was going to sue the other person $\cdots$ they drew up a legal complaint. (S7)

Theme 3. Hidden resentment towards dependent hierarchical relationships

We couldn't sit against the back of the chair $\cdots$ seniors made us close our eyes $\cdots$ there was no violence, but they made a scary atmosphere $\cdots$ it was really terrifying. (S1)

I was originally a bit opinionated, I enjoyed speaking up and liked to get involved in the decision-making process, but it gradually became impossible ... I've got a close classmate who tells me 'Don't come out front and speak like that.' That made me a bit intimidated. (S7)

We had an event called a 'greeting ceremony' and we told freshmen to wear suits. It's like a tradition and I followed it when I was freshman and I felt there was nothing wrong with it $\cdots$ But the professor probably thought that it was really oppressive. I don't really understand $\cdots$. But now I just have to follow the professor's opinion $\cdots$ he doesn't really listen to 
the students. (S3)

I was a little bit too scared to see a professor to ask something. Of course, he would be nice $\cdots$ । remember the time when I got really scolded by a professor. I did my best to prepare but couldn't answer a single question that the professor asked. I felt really ashamed. (S13)

The residents are mostly difficult ... They're like gods ... it's really hard to ask them anything ... we often get scolded when we go home without permission or act without getting confirmation. (S13)

The professor and I really have different personalities. One of my preceptors was really rough and his words were rough, too. We had dinner at a restaurant. He asked for a paper cup for ash and smoked in a no smoking area. He bragged about himself and ignored [others]. (S10)

I sent a message to him [a professor] at 9:30 PM about the time of morning rounds. In the reply, he scolded me a lot telling me it was not polite to send a message at that late hour ... You can check text messages whenever you're available. So, I didn't really think it was rude. I'm not so sure 9:30 PM was such a late hour $\cdots$ When I told my peers this story, everyone was like, 'Is 9:30 PM that late?' (S9)

Theme 4. No hesitation to speak up about gender issues lor gender inequality)

I didn't really used to empathize with gender issues. I've never experienced any of that. Now, I feel them more than any other time. A lot of departments want to hire men. Recently, one of the residents in my internal medicine department ran away. And a male resident also did so in another department. When a woman runs away, it's because she's a woman. But when a man does it, it's because the work is hard $\cdots$ I think a lot of times that I wish these stereotypes would disappear. (S6)

Two students were in a relationship and there was a rumor that the girl got caught by a night guard while having sex with another man at school $\cdots$ but the rumor is really not accurate. They were together in a room, but the rumor spread through the entire class group, residents and professors. But the girl was mostly the only one who was talked about ... [Women] are always the weak one. (S7)

I hear guys complaining that they're the victims of reverse discrimination. For example, interns and residents call their juniors out when they have days-off. Then usually male students are the ones who get that call. They [have to] go there and drink a lot even if they don't want to. But that's not women's fault. But guys think that they have serious a disadvantage and often say that they'll get it compensated when they start [working] in hospital. (S6)

We have to make calls to the seniors before a club meeting. Someone says 'I only want a woman to call me.' Another says 'I want to sit next to a woman.' These seniors get drunk and become touch-feely like [putting an arm] around a shoulder. Even male students are really upset about it, too. But there are some who don't care. For example, a male student said 'I've had too many drinks with that senior so you go ahead and sit next to him for a while.' That student didn't think that the female student might be a bit offended. He just wanted to share the load. (S6)

The friend whom I like $\cdots$ she is quite interested in feminism. She read a lot about feminism and joind something like a human rights club outside. (S7)

In many cases, men mostly do hard work. I'm a member of an orchestra club and we have a lot of physical work such as setting up a stage in advance or moving musical instruments. So, men have no choice but to work more. (S6)

A friend of mine was about to move up to the third year and said so in front of a professor. And he [the professor] said, 'in our time, women in third grade were considered to be almost menopausal. Third year female students were menopausal.' At that time, we talked with each other about how a word like menopause could be used in such way. (S7)

Women and men drank together at a school club party, and a girl got too drunk and a male student walked her out $\cdots$ and in the meantime, it was said that she was 'forced', I mean, had intercourse. She wanted to push it to court but [in the end] settled it with the man $\cdots$ one female senior told us, 'women should learn how to control themselves at a drinking party. No matter what, that's the women's responsibility.' (S4) 